\title{
Pathways to Reading: The Role of Oral Language in the Transition to Reading
}

\author{
NICHD Early Child Care Research Network
}

\begin{abstract}
What is the role of oral language in reading competence during the transition to school? Is oral language in preschool best conceptualized as vocabulary knowledge or as more comprehensive language including grammar, vocabulary, and semantics? These questions were examined longitudinally using 1,137 children from the National Institute of Child Health and Human Development Study of Early Child Care and Youth Development. Children were followed from age 3 through 3rd grade, and the results suggest that oral language conceptualized broadly plays both a direct and an indirect role in word recognition during the transition to school and serves as a better foundation for early reading skill than does vocabulary alone. Implications of these findings are discussed in terms of both theoretical models of early reading and practical implications for policy and assessment.
\end{abstract}

Learning to read successfully is heavily dependent on mastery of a number of basic perceptual, cognitive, and language processes, including phonological, orthographic, syntactic, semantic, and comprehension skills (Biemiller, 1999; Snow, Burns, \& Griffin, 1998). Recent research (summarized in Shonkoff \& Phillips, 2000) demonstrates that significant variability in aspects of children's early literacy emerges during the preschool years. Hence there is increasing recognition that literacy development starts long before children begin formal instruction in school and that later reading success is powerfully affected by the skills children acquire during these formative years.

This study was directed by a steering committee and supported by the National Institute of Child Health and Human Development (NICHD) through a cooperative agreement (U10) that calls for scientific collaboration between the grantees and the NICHD staff. Participating investigators, listed in alphabetical order, are as follows: Jay Belsky, Birkbeck College, University of London, London, England; Cathryn L. Booth-LaForce, University of Washington; Robert Bradley, University of Arkansas at Little Rock; Celia Brownell, University of Pittsburgh; Margaret Burchinal, University of North Carolina at Chapel Hill; Susan B. Campbell, University of Pittsburgh; K. Alison Clarke-Stewart, University of California, Irvine; Sarah L. Friedman, NICHD, Bethesda, MD; Kathryn Hirsh-Pasek, Temple University; Bonnie Knoke, Research Triangle Institute, Research Triangle Park, NC; Nancy Marshall, Wellesley College; Kathleen McCartney, Harvard University; Frederick J. Morrison, University of Michigan; Marion O'Brien, University of North Carolina at Greensboro; Margaret Tresch Owen, University of Texas at Dallas; C. Chris Payne, University of North Carolina at Greensboro; Robert Pianta, University of Virginia; Susan Spieker, University of Washington; Deborah Lowe Vandell, University of Wisconsin-Madison; and Marsha Weinraub, Temple University. Ageliki Nicolopoulou, Lehigh University, also served as a consultant and serves as a corporate author.

We express our appreciation to the study coordinators at each site, who supervised the data collection; the research assistants, who collected the data; and especially the families and child-care providers, who welcomed us into their homes and workplaces and cooperated willingly with our repeated requests for information.

Correspondence concerning this article should be addressed to NICHD Early Child Care Research Network, NICHD, 6100 Executive Boulevard, Room 4B05, Rockville, MD 20852.
Although these findings are relatively uncontroversial, there is current uncertainty about which "emergent literacy" skills are foundational for early reading success and about the manner in which different component skills contribute to shaping literacy acquisition (Dickinson, McCabe, Anastasopoulos, PeisnerFeinberg, \& Poe, 2003; Schatschneider, Fletcher, Francis, Carlson, \& Foorman, 2004; Storch \& Whitehurst, 2002; Whitehurst \& Lonigan, 1998). Two broad classes of skills have been identified as important for later reading performance: code-related skills and oral language skills (Storch \& Whitehurst, 2002; Whitehurst \& Lonigan, 1998). Code-related processes can include skills such as phonological awareness, letter naming, phonological decoding, emergent writing, and print awareness. Oral language processes encompass various skill sets including vocabulary (receptive and expressive), syntactic and semantic knowledge, and narrative discourse processes (memory, comprehension, and storytelling). These two domains of skill are separable statistically and relate to later reading in unique ways (Storch \& Whitehurst, 2002). The questions arising from recent research are how and when coderelated and oral language skills exert an influence on reading acquisition. Answers to these questions not only drive our understanding of the mechanisms of reading development but also influence the kinds of assessments and interventions that will be used to promote reading development. The present study addresses these questions.

\section{Emergent Literacy and Reading}

Research conducted over the past two decades paints a complex picture of the skills undergirding the growth of literacy skill during the preschool years as well as an intricate portrait of the associations among these emerging skills and later reading development. Perhaps the most well-researched and well-documented association is that between phonological awareness (particularly phonemic awareness) and reading performance (for overviews, see Dickinson et al., 2003, and Schatschneider et al., 2004). Yet, accumulating evidence finds that reading relates to a significant number of different processes including letter naming, vocabulary (see Whitehurst \& Lonigan, 2001, for review), syntactic and se- 
mantic knowledge (Scarborough, 2001), and narrative skills (Vernon-Feagans, Hammer, Miccio, \& Manlove, 2001). In turn, these component skills are interrelated and may influence different aspects of reading at different points in time. For example, Dickinson et al. (2003) found significant associations among measures of print awareness, vocabulary, and phonological sensitivity. Moreover, findings from Storch and Whitehurst (2002) revealed that the direct association between oral language skills, including vocabulary and accuracy of word decoding, disappeared after kindergarten but that oral language reemerged to significantly predict reading comprehension in third to fourth grade. A similar finding was reported by Senechal and LeFevre (2002).

\section{The Role of Oral Language}

Partly as a consequence of these complex relations, researchers differ in the role they accord oral language in early reading development. Several investigators have reported that once phonological awareness is taken into account, the influence of oral language skills in early reading is negligible. For instance, Bryant, MacLean, \& Bradley (1990) demonstrated that measures of syntactic and semantic knowledge did not uniquely predict first-grade reading scores once phonological processing was accounted for (see also Roth, Speece, Cooper, \& de la Paz, 1996). Others (e.g., Vellutino et al., 1996) have contended that when relations are found with oral language, they may reflect the impact of verbal intelligence, which has not been uniformly controlled across studies (Storch \& Whitehurst, 2002).

In a series of recent investigations, Whitehurst and colleagues (Storch \& Whitehurst, 2001, 2002; Whitehurst \& Lonigan, 1998) found evidence that oral language skills have only an indirect influence on the accuracy of word decoding in early elementary school reading performance. Elementary school reading is mediated by the effect of language on code-related skills such as letter naming. Oral skills feed into code skills such as print principles, phonological awareness, and emergent writing, which in turn form the foundation for early reading success. Once the child has mastered these coding skills, oral language plays a dual role by supporting not only decoding but also an understanding of the text (Storch \& Whitehurst, 2002). As a group, these researchers have downplayed the role of oral language during the transition to school, either failing to find any unique predictive relation to first-grade reading or finding an indirect association to reading through code skills.

In contrast, other researchers have found evidence that oral language skills play a crucial role in reading acquisition independent of phonological skills (Bishop, 1991; Scarborough, 1990; Share \& Leikin, 2004; Tunmer, Herriman, \& Nesdale, 1988; Tunmer \& Nesdale, 1985). In one study, Catts, Fey, Zhang, and Tomblin (1999) found that both oral language and phonological processes independently predicted word decoding in kindergartners. Other investigators have found that, in children with reading problems, oral language difficulties with syntax (Bishop \& Adams, 1990) and semantic relations (Menyuk et al., 1991) most strongly predicted reading performance. More recently, Dickinson et al. (2003) reported that vocabulary played a role in early reading competence even when phonological sensitivity was controlled. Taken together, these studies not only suggest a direct relationship between oral language and reading in elementary school, but they also raise questions about the nature of oral language that relate to elementary school reading. Is oral language best represented by vocabulary knowledge or by more comprehensive language ability in grammar, semantics, and narrative, among other areas?

In attempting to reconcile these discrepant findings about the role oral language plays in reading, investigators have noted a number of differences across studies (Storch \& Whitehurst, 2002). First, as Catts et al. (1999) pointed out, there is inconsistency in whether the reading outcome of interest is word recognition or reading comprehension. There is emerging evidence, reviewed above, that oral language skills play a crucial role in the growth of comprehension skills, whereas their impact on decoding skills is less clear. Second, Storch and Whitehurst (2002) noted that, in prospective studies of children with language disorders or retrospective studies of children with reading disorders, insufficient attention has been given to the possibility that some percentage of these children have general developmental delays. Third, there are inconsistencies in how researchers assess oral language. In many studies, oral language is either exclusively measured through or is heavily weighted toward vocabulary knowledge. Yet, a number of researchers have posited that the power of oral language on all aspects of reading comes from a more comprehensive view of language that includes narrative, semantics, and syntax (see Dickinson \& Tabors, 2001, or Dickinson et al., 2003, for a review). Fourth, there are few studies that have looked at language-reading relations in a longitudinal sample over an extended developmental period (Storch \& Whitehurst, 2002). Most studies extend only from kindergarten to second grade, with a minority starting at 4 years of age. One problem with this strategy is that it is difficult, even with a longitudinal design, to evaluate the direction of influence of language and code-based skills. Although most investigators tend to conceptualize the association as stemming from oral language's influence on code-based processes, clearly the reverse is also possible. Dickinson et al. (2003) pointed out that growth of phonological skills could serve to enhance the development of vocabulary through its effect on word analysis. Finally, a crucial issue in this research is reflected in the fact that a predominance of recent work has used low-income, high-risk children, such as those in Head Start. As several authors have noted (e.g., Storch \& Whitehurst, 2002), it is not clear to what extent the patterns of association found in these studies would generalize to a more normative population of children.

\section{The Present Study}

Using structural equation modeling and a large, normative sample of children drawn from the National Institute of Child Health and Human Development (NICHD) Study of Early Child Care and Youth Development, we attempted to address these concerns in a prospective investigation of the contribution of preschool oral language skills to reading performance in early elementary school. Several features of this study are notable. First, we included measures of both word recognition and reading comprehension in an effort to specify more precisely which aspect of reading is most strongly associated with oral language. Second, the study included both comprehensive oral language assessments as well as vocabulary assessment, thus disentangling relationships between the type of oral language skill and reading development. Third, the present study spanned the age range from 3 years to third grade, 
permitting assessment of the role of language over a substantial time period. In that regard, we included oral language measures taken when the children were 36 months of age, well before most children have developed any functional level of phonological awareness (though see Chaney, 1998). This allowed us to examine more clearly the direction of influence of early oral language on later language and phonological skills. Finally, the NICHD sample was selected to minimize the inclusion of developmental delays and disorders and to test the question on a normative and diverse sample. Because the sample was so large and economically diverse, it was also possible to test whether relationships that held for the entire sample were also evident in subsamples of children from higher or lower socioeconomic brackets.

\section{The Model}

Figures 1 and 2 depict the working models tested in the present study. Figure 1 represents the indirect model, in which preschool oral language is predicted to relate to reading in early elementary school through code skills such as phonological knowledge and word recognition. Figure 2 represents the comprehensive model, in which oral language is projected to influence reading in first grade both directly and indirectly. Note that only one additional pathway, the direct path from oral language at 54 months to first-grade code skills separates the two models. Depicted in both models are assessments of oral language including both broad language assessments at 36 and 54 months of age and measures of vocabulary at 54 months of age and first grade. Consistent with the work of
Storch and Whitehurst (2002; and with that of Whitehurst \& Lonigan, 2001), code learning includes measures of phonological knowledge at 54 months and first grade as well as word decoding and recognition skills at 54 months and first grade. Finally, reading comprehension was assessed at third grade.

We predicted that the comprehensive model would better account for the relations between language and reading than would the indirect model. Thus, oral language assessed at 36 months was predicted to relate independently to both oral language and code skills at 54 months, just prior to school entry in both models. There is no controversy in the field with respect to this relationship, because it is assumed that reading skills are built on language in the earliest years. More controversial is the question about how these code skills, once developed, differentially relate to later reading abilities. That is, do the code skills mediate the relationship between oral language and later reading, or does oral language in late preschool relate more directly to later reading? We predicted that oral skills would make a unique contribution to concurrent and later reading comprehension. We anticipated that they would correlate with each other at 54 months. Oral language skills at 54 months should also reliably predict reading comprehension scores at third grade even in the presence of significant associations between oral language skills at first grade and code skills (word recognition) at 54 months of age. Finally, and critically important to the present discussion, we expected that within the oral language skills, broad language skills would be more predictive of later reading than would vocabulary scores alone and that

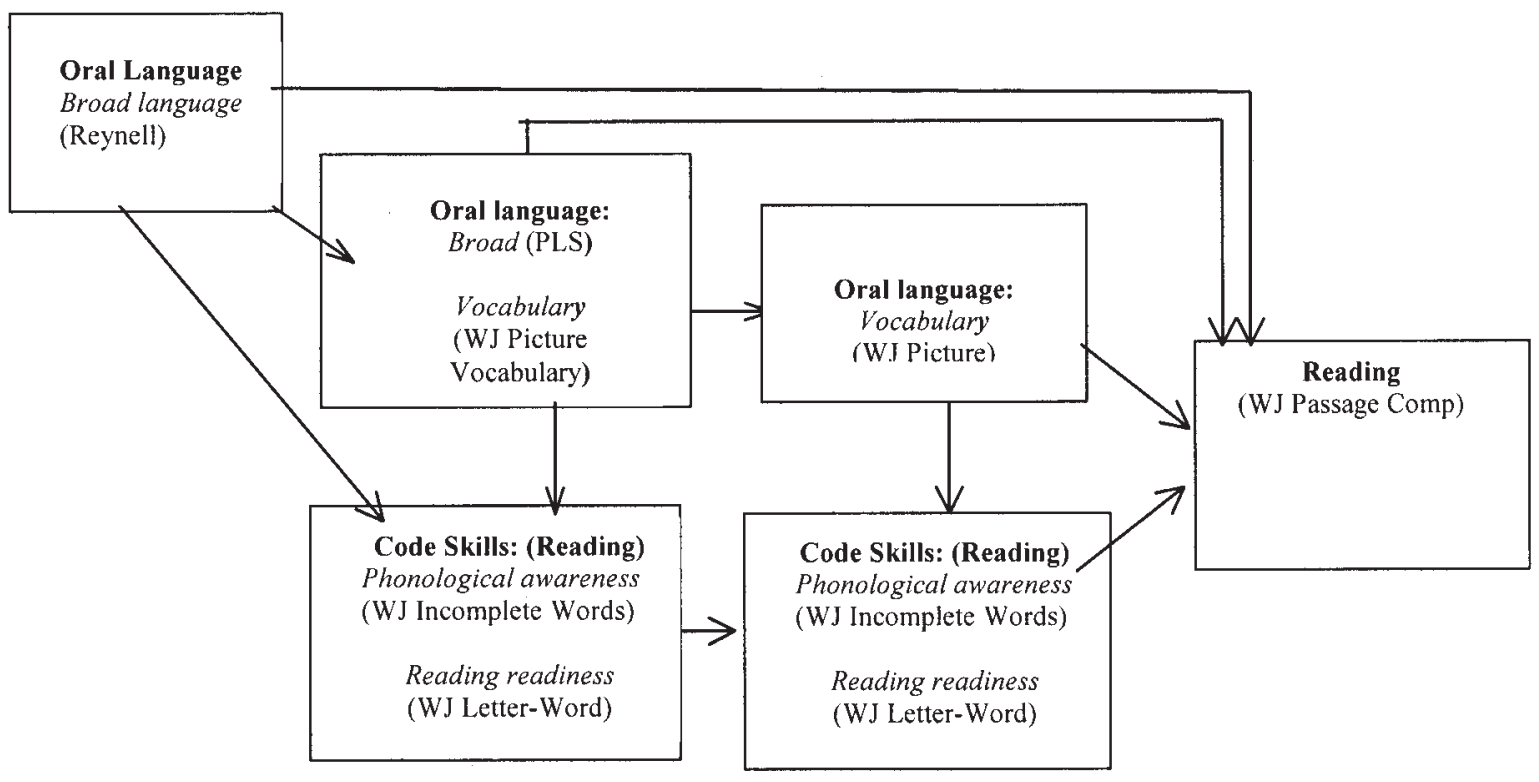

$36 \mathrm{mo.}$

54 mo.

1st grade

3rd grade

Figure 1. Schematic of indirect model of the role of oral language in early reading: Preschool language plays an indirect role in first-grade reading skills. Reynell $=$ Reynell Developmental Language Scales; PLS = Preschool Language Scale; WJ = Woodcock-Johnson Psycho-Educational Battery-Revised; Comp = Comprehension. 


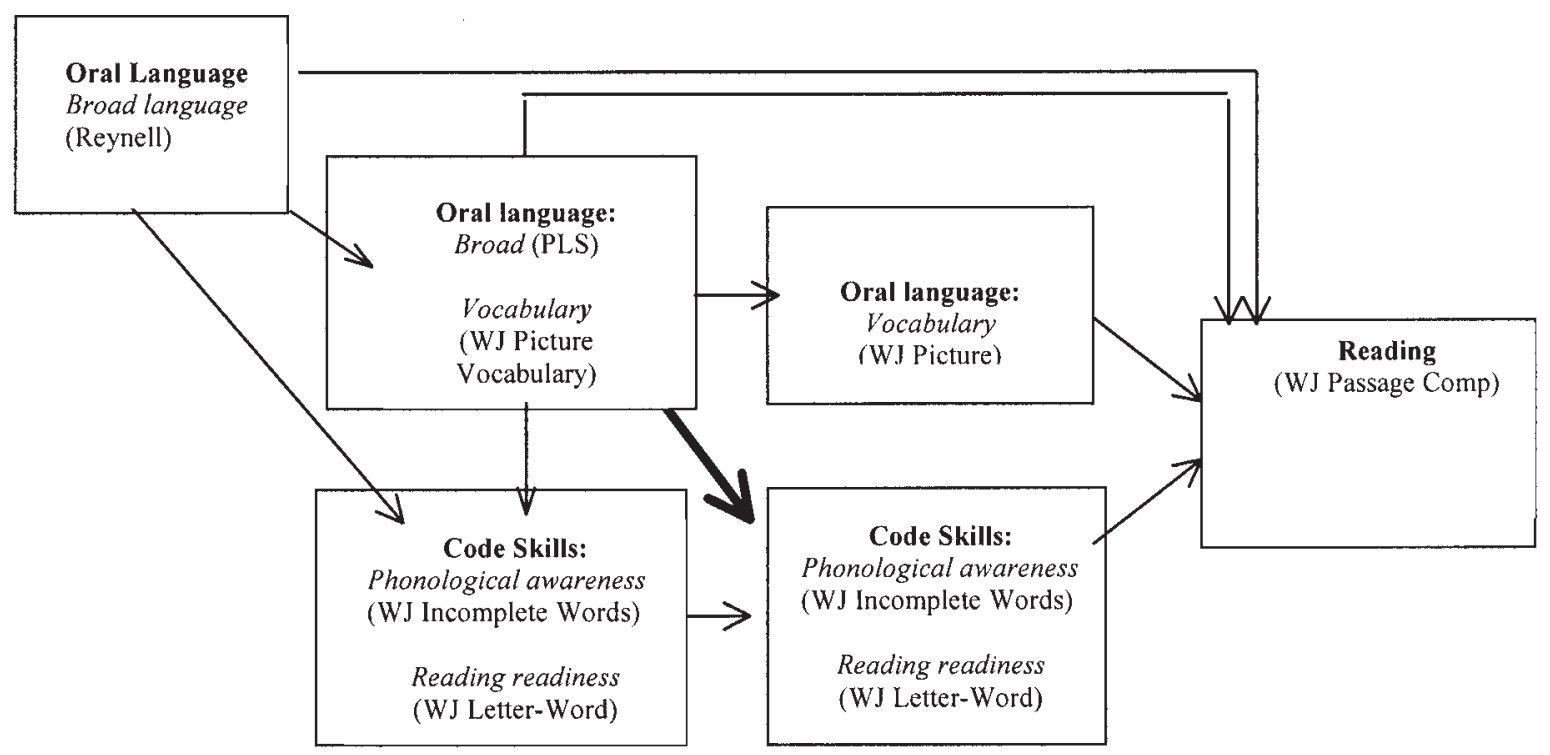

$36 \mathrm{mo}$.

54 mo.

1 st grade

3rd grade

Figure 2. Schematic of comprehensive model of the role of oral language in early reading: Preschool language plays both an indirect role and a direct role in first-grade reading skills. Reynell $=$ Reynell Developmental Language Scales; PLS = Preschool Language Scale; WJ = Woodcock-Johnson Psycho-Educational BatteryRevised; Comp $=$ Comprehension.

this effect would hold not only for the broader sample when taken collectively but also for children in both higher and lower income families. Thus, at 54 months, we predicted that final broad language skills would directly and significantly predict word recognition scores in first grade, as would phonological knowledge, with the impact of vocabulary dropping out. In summary, in the present study we sought to elucidate the independent and interactive roles of oral language skills and phonological skills in word recognition and reading comprehension in a normative sample of children across the age range from 3 to 9 years.

\section{Method}

\section{Study Design}

Data from the NICHD Study of Early Child Care and Youth Development offered a unique opportunity to test the predictions raised above. The NICHD study is a prospective longitudinal study of a large, geographically, ethnically, and economically diverse sample of children born in 1991 and their families. The data collected in the study include multiple indicators of family, child-care, and school contexts along with multiple measures of child characteristics and child psychological and behavioral outcomes (NICHD Early Child Care Research Network, 2001, and http://secc .rti.org).

\section{Participants}

For the current study, analyses are based on data from 1,137 children (of 1,364 enrolled in the study at birth) for whom there were multiple language and academic assessments from 36 months through third grade. Children participating in the NICHD Study of Early Child Care and Youth Development were born in hospitals at 10 data collection sites across the United States and were followed from birth through third grade. Families were recruited through hospital visits to mothers shortly after the children's births in 1991. During selected 24-hr intervals, all women giving birth were screened for eligibility and willingness to be contacted again. Of the 8,986 mothers who gave birth during the sampling period, 5,416 (60\%) agreed to be telephoned in 2 weeks and met the eligibility requirements (mother over 18, mother spoke English, mother healthy, baby not part of a multiple birth or released for adoption, lived within an hour of research site, neighborhood not unsafe). Of that group, a conditionally random sample of 3,015 was selected $(56 \%)$ for the phone call. At these calls, families were excluded if the infant had been in the hospital more than 7 days, if the family expected to move in the next 3 years, or if they could not be reached with at least three attempts at contact. A total of 1,526 who were selected for the call were also eligible and agreed to an interview; of these, 1,364 completed a home interview when the infant was 1 month old and became the study participants. The resulting sample was diverse, including $24 \%$ ethnic minority children, $11 \%$ mothers who had not completed high school, and $14 \%$ single-parent mothers. The subsample of 1,137 children in this study includes those families for whom there are child outcome data at 54 months, first grade, or third grade. These children and their families were compared with the children who were excluded because of attrition in the sample. Compared with children who were excluded, the children included in this analysis had mothers with more education, larger vocabularies, and larger incomes during the preschool years. Mothers of the children in this sample had an average of 14.4 years of education $(S D=2.78)$, with $38 \%$ having at least a college degree and $28 \%$ having only a high school degree. Twenty-three percent of the mothers were not married. Average family 
income for this sample was three times the poverty threshold $(S D=3.08)$. Twenty-five percent had an income-to-needs ratio of less than 2 and were thus considered to be of low income $(n=287) ; 40 \%(n=450)$ were at middle-income levels, with an income-to-needs ratio between 2 and 4; and $35 \%(n=398)$ were of high income, with income-to-needs ratios above 4. Thus, the sample used in this study was economically diverse. The sample was also ethnically diverse. Of the 1,137 families, $11.8 \%(n=134)$ were Black, $6 \%$ were Hispanic, and $77 \%$ were White. Although this sample is not a nationally normed sample and exhibited nonrandom attrition, it does reflect a diverse range of family backgrounds and socioeconomic levels present in the United States.

\section{Overview of Measures}

\section{Control Measure}

One control measure was included in the analysis of first- and thirdgrade reading: a measure of maternal verbal intelligence. This construct served as a proxy for the genetic shared variance in maternal and child intelligence and possibly for the richness of the language environment. Maternal verbal intelligence was examined using the Peabody Picture Vocabulary Test (PPVT; Dunn \& Dunn, 1981), which was administered to mothers when the children were 36 months of age.

\section{Language Measures}

Comprehensive oral language development. Two measures of broad language ability were included in this battery. Both examine children's language processing skills in syntax, vocabulary, morphology, and communicative ability. The Reynell Developmental Language Scales (Reynell \& Gruber, 1977), administered at 36 months of age, measure both expressive language and verbal comprehension. For the purposes of this article, these scores were averaged to create a Reynell total score with a mean standard score of 100 and a standard deviation of 15. At 54 months, broad language ability was assessed using the Preschool Language Scale (PLS-3; Zimmerman, Steiner, \& Pond, 1979). It assesses a range of language behaviors grouped into two subscales: Auditory Comprehension and Expressive Language ( $r=.70, p<.01$, in our sample). The test is standardized to have a mean of 100 and a standard deviation of 15 . For the total language score, $\alpha=.95$ in our sample.

Vocabulary development. Children's vocabulary performance (comprehension-knowledge) was examined at 54 months and in first grade using the Picture Vocabulary subtest of the Woodcock-Johnson PsychoEducational Battery—Revised (WJ-R; Woodcock \& Mather, 1989, 19891990). With a mean of 100 and a standard deviation of 15 , the Picture Vocabulary subtest measures the ability to recognize or to name pictured objects ( $\alpha=.76$ in our sample). The first six items are in a multiple-choice format. The child is asked to point to the picture that shows the object mentioned by the examiner. Subsequent items require the child to name familiar and unfamiliar pictured items.

\section{Code-Related Processes}

Phonological awareness. Phonological awareness was assessed with the Incomplete Words subtest of the WJ-R (Woodcock \& Mather, 1989, 1989-1990). Research suggests that phonological processing might be the route through which language relates to first-grade reading (Roth et al., 1996; Whitehurst \& Lonigan, 2001). In this test of auditory closure, the child listened to an audiotape with words that had one or more phonemes missing and was required to name the complete words $(\alpha=.86$ in our sample). This task requires children not only to isolate particular phonemes in the word but also to use metalinguistic skills that permit them to manipulate the phonemes that they hear. For example, children might listen to the incomplete word $b a . \ldots t u b$ and be asked what word the person was trying to say (e.g., baTHtub). The only way to complete this task is to have some phonological knowledge about the word segments and to be able to isolate and remove the particular word segment requested by the experimenter. Whitehurst and Lonigan (2001) wrote, "Phonological processing refers to activities that require sensitivity to, manipulation of, or use of the sounds in words" (p. 15). This test meets this definition and hence was used to examine phonological sensitivity or phonemic awareness in this sample.

Reading achievement at 54 months, first grade, and third grade. Academic achievement in decoding skills and reading was assessed with two subtests from the WJ-R (Woodcock \& Mather, 1989, 1989-1990) that document children's performance in reading. For each of the subtests, standard scores were computed $(M=100, S D=15)$.

Decoding skills and word recognition were examined at 54 months and in first grade using the Letter-Word Identification subtest of the WJ-R. The first five items involve symbolic learning or the ability to match a pictographic representation of a word with an actual picture of the object. The remaining items require identification of isolated letters and words that appear in large type. Reading comprehension was examined in third grade using the Passage Comprehension subtest of the WJ-R. In this task, children read a series of passages and are asked to supply the missing words.

\section{Data Analysis Plan}

The analysis plan was designed to test how and when code-related skills and oral language skills relate to reading acquisition from prior to kindergarten entry through third grade. The two models shown in Figures 1 and 2 were contrasted. The first model, the indirect model, assumes that early oral language is related to both coding skills and oral language at 54 months but that only coding skills at 54 months predict language and reading skills in first grade, which in turn predict reading comprehension in third grade. The comprehensive model, in contrast, assumes that language will have both an indirect effect and a direct effect when predicting from preschool language to reading ability in early elementary school. It further assumes that the broad language measures at 54 months will provide better predictions of later reading than will the correlated measure of vocabulary.

The specified models were tested using the AMOS Version 4.0 program (Arbuckle, 1997). Maximum-likelihood estimates using the full information and the listwise deletion of missing data were requested. Indirect paths were tested using a $t$ statistic developed by Sobel (1982). Multiple indices of fit were examined ( $\mathrm{Hu} \&$ Bentler, 1999). In addition to the overall goodness-of-fit chi-square statistic, we selected measures that are less sensitive to latent structure and measurement model misspecification $(\mathrm{Hu}$ $\&$ Bentler, 1999). The standardized root mean squared residual (SRMR) is an absolute fit index that measures how well the sample covariance structure fits the proposed model's covariance structure, with a value less than or equal to .08 representing good fit. The root-mean-square error of approximation (RMSEA; Browne \& Cudek, 1993; Steiger \& Lind, 1980) is also an absolute fit index, with a value of .06 or less representing a good fit. Bollen's goodness-of-fit index (see Bollen, 1990) is an incremental fit index that measures the proportion of improvement in fit between the model and a null model, with a value of .95 or greater representing a good fit.

\section{Results}

Descriptive statistics for the variables used in the analyses are listed in Tables 1 and 2. Table 1 lists the sample size, mean, and standard deviations for all measures included in the analyses. We used the full information missing data imputation option in AMOS, so sample sizes vary slightly across variables. Table 2 lists the correlations.

\section{The Indirect and Comprehensive Models: A Comparison}

To address the first question about the relationship between the two models, we used a chi-square difference test to compare the fit 
Table 1

Descriptive Statistics: Longitudinal Assessments of Oral Language, Coding Skills, and Reading

\begin{tabular}{lrrrc}
\hline \multicolumn{1}{c}{ Variable } & $N$ & $M$ & \multicolumn{1}{c}{$S D$} & Range \\
\hline Maternal vocabulary (PPVT) & 1,078 & 99.46 & 18.3 & $40-159$ \\
Oral language & & & & \\
$\quad$ Reynell total score, 36 months & 1,071 & 97.67 & 13.5 & $62-131.5$ \\
$\quad$ Preschool Language Scale total score, 54 months & 1,045 & 99.77 & 20.3 & $50-137$ \\
$\quad$ WJ-R Picture Vocabulary, 54 months & 1,055 & 100.33 & 15.0 & $10-143$ \\
$\quad$ WJ-R Picture Vocabulary, Grade 1 & 1,020 & 105.46 & 15.6 & $44-150$ \\
Coding skills & 1,046 & 96.70 & 13.6 & $57-132$ \\
$\quad$ WJ-R Incomplete Words, 54 months & 1,052 & 98.94 & 13.4 & $63-150$ \\
WJ-R Letter-Word Identification, 54 months & 1,018 & 95.92 & 11.2 & $39-136$ \\
$\quad$ WJ-R Incomplete Words, Grade 1 & 1,025 & 111.98 & 15.8 & $51-150$ \\
$\quad$ WJ-R Letter-Word Identification, Grade 1 & & & & \\
Reading & 1,011 & 112.80 & 14.0 & $47-147$ \\
$\quad$ WJ-R Passage Comprehension, Grade 3 & & & & \\
\hline
\end{tabular}

Note. $\quad$ PPVT $=$ Peabody Picture Vocabulary Test; Reynell $=$ Reynell Developmental Language Scales; WJ-R = Woodcock-Johnson Psycho-Educational Battery-Revised.

for Figure 1 (the indirect model constraining the direct roles of oral language both at 36 and 54 months in first-grade reading) with the fit for Figure 2 (the comprehensive model that allowed for a direct role of language in first-grade reading). The results suggest that the comprehensive model permitting a direct role for language offers a significantly better fit for the data, $\chi^{2}(3)=11.87, p<.05$. This is impressive given that only one additional pathway differentiated the two models.

\section{The Comprehensive Model: Language and Coding Skills Relate Directly and Indirectly to Reading}

Indeed, the comprehensive model fit the data very well. This model included paths from 36-month language to all other variables; from 54-month language variables to all Grade 1 variables and Grade 3 reading comprehension; from 54-month coding skills to all Grade 1 variables; and from all Grade 1 variables to Grade 3 reading comprehension. Preliminary analyses demonstrated that 54-month coding skills were not directly associated with Grade 3 reading, and those paths were eliminated from the comprehensive model. Measures collected at the same age were allowed to have correlated errors. Maternal vocabulary scores from the PPVT were entered as a control variable by allowing paths between this variable and all other variables. This model resulted in a Bollen goodness-of-fit index of .99, an SRMR of .005, an RMSEA of .055 , and an overall fit of $\chi^{2}(2)=5.74, p=.07$. The model was nearly saturated, so the fit indices need to be interpreted cautiously. The unstandardized and standardized direct path coefficients appear in Table 3. Unstandardized indirect path coefficients from this analysis are shown in Table 4, and the paths with significant coefficients are shown in Figure 3.

\section{How Is Early Language Related to Early Reading (WJ-R Letter-Word Identification)?}

Evidence supporting a direct role of language in early reading (WJ-R Letter-Word Identification) was obtained when we compared the fit of the comprehensive model with a model that eliminated paths from the 36-month comprehensive measure and the two 54-month language measures to first-grade WJ-R Letter-

Table 2

Correlations Among Longitudinal Assessments of Oral Language, Coding Skills, and Reading

\begin{tabular}{|c|c|c|c|c|c|c|c|c|c|c|}
\hline Measure & 1 & 2 & 3 & 4 & 5 & 6 & 7 & 8 & 9 & 10 \\
\hline 1. Maternal PPVT & - & .45 & .49 & .48 & .28 & .35 & .52 & .22 & .28 & .43 \\
\hline 36-month measure & & & & & & & & & & \\
\hline 2. Reynell language total & & - & .73 & .54 & .44 & .46 & .51 & .35 & .36 & .49 \\
\hline 54-month measures & & & & & & & & & & \\
\hline 3. Preschool Language Scale total & & & - & .63 & .48 & .53 & .58 & .39 & .37 & .57 \\
\hline 4. WJ-R Picture Vocabulary & & & & - & .40 & .48 & .51 & .35 & .32 & .51 \\
\hline 5. WJ-R Incomplete Words & & & & & - & .38 & .34 & .38 & .34 & .39 \\
\hline 6. WJ-R Letter-Word Identification & & & & & & - & .47 & .31 & .56 & .54 \\
\hline Grade 1 measures & & & & & & & & & & \\
\hline 7. WJ-R Picture Vocabulary & & & & & & & - & .34 & .37 & .56 \\
\hline 8. WJ-R Incomplete Words & & & & & & & & - & .34 & .39 \\
\hline 9. WJ-R Letter-Word Identification & & & & & & & & & - & 67 \\
\hline Grade 3 measure & & & & & & & & & & \\
\hline 10. WJ-R Passage Comprehension & & & & & & & & & & - \\
\hline
\end{tabular}

Note. $\quad$ PPVT $=$ Peabody Picture Vocabulary Test; Reynell $=$ Reynell Developmental Language Scales; WJ-R = Woodcock-Johnson Psycho-Educational Battery-Revised. 
Table 3

Unstandardized and Standardized Direct Path Coefficients for the Comprehensive Model

\begin{tabular}{|c|c|c|c|}
\hline Path & $B$ & $S E$ & $\beta$ \\
\hline \multicolumn{4}{|l|}{ From Reynell total language 36 months to } \\
\hline PLS total language 54 months & $.97 * *$ & .03 & .65 \\
\hline WJ-R Vocabulary 54 months & $.46^{* *}$ & .03 & .42 \\
\hline WJ-R Incomplete Words 54 months & $.45^{* *}$ & .03 & .44 \\
\hline WJ-R Letter-Word 54 months & $.39 * *$ & .03 & .39 \\
\hline WJ-R Vocabulary Grade 1 & $.11 *$ & .04 & .10 \\
\hline WJ-R Incomplete Words Grade 1 & .05 & .04 & .06 \\
\hline WJ-R Letter-Word Grade 1 & .05 & .05 & .04 \\
\hline WJ-R Passage Comprehension Grade 3 & .04 & .04 & .05 \\
\hline \multicolumn{4}{|l|}{ From PLS total language 54 months to } \\
\hline WJ-R Vocabulary Grade 1 & $.07 *$ & .03 & .09 \\
\hline WJ-R Incomplete Words Grade 1 & $.06^{*}$ & .03 & .10 \\
\hline WJ-R Letter-Word Grade 1 & $.08 *$ & .04 & .10 \\
\hline WJ-R Passage Comprehension Grade 3 & $.07 * *$ & .03 & .10 \\
\hline \multicolumn{4}{|l|}{ From WJ-R Vocabulary 54 months to } \\
\hline WJ-R Vocabulary Grade 1 & $.43^{* *}$ & .03 & .09 \\
\hline WJ-R Incomplete Words Grade 1 & $.11^{* *}$ & .03 & .14 \\
\hline WJ-R Letter-Word Grade 1 & -.02 & .04 & -.02 \\
\hline WJ-R Passage Comprehension Grade 3 & $.08 * *$ & .03 & .20 \\
\hline \multicolumn{4}{|l|}{ From WJ-R Incomplete Words 54 months to } \\
\hline WJ-R Vocabulary Grade 1 & -.006 & .03 & -.01 \\
\hline WJ-R Incomplete Words Grade 1 & $.18^{* *}$ & .03 & .22 \\
\hline WJ-R Letter-Word Grade 1 & $.11 * *$ & .04 & .10 \\
\hline \multicolumn{4}{|l|}{ From WJ-R Letter-Word 54 months to } \\
\hline WJ-R Vocabulary Grade 1 & $.15^{* *}$ & .03 & .13 \\
\hline WJ-R Incomplete Words Grade 1 & $.08 * *$ & .03 & .10 \\
\hline WJ-R Letter-Word Grade 1 & $.54 * *$ & .04 & .46 \\
\hline \multicolumn{4}{|l|}{ From WJ-R Vocabulary Grade 1 to } \\
\hline WJ-R Passage Comprehension Grade 3 & $.18^{* *}$ & .03 & .20 \\
\hline \multicolumn{4}{|l|}{ From WJ-R Incomplete Words Grade 1 to } \\
\hline WJ-R Passage Comprehension Grade 3 & 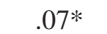 & .03 & .05 \\
\hline \multicolumn{4}{|l|}{ From WJ-R Letter-Word Grade 1 to } \\
\hline WJ-R Passage Comprehension Grade 3 & $.42 * *$ & .02 & .08 \\
\hline
\end{tabular}

Note. $\quad$ Reynell $=$ Reynell Developmental Language Scales; PLS $=$ Preschool Language Scale; WJ-R = Woodcock-Johnson Psycho-Educational Battery-Revised.

$* p<.05$. ** $p<.01$.

Word performance. Therefore, we looked at both direct and indirect paths from language to reading skills. Indirect paths were tested using the MacKinnon approach to computing asymmetric confidence limits (MacKinnon, Lockwood, Hoffman, West, \& Sheets, 2002)

There was considerable evidence in the comprehensive model linking prekindergarten language to first-grade reading skills both directly and indirectly. First, the direct path from 54-month broad language to first-grade decoding $(\beta=.10, p<.01)$ was statistically significant, indicating that broad language skills prior to kindergarten provided independent prediction of reading skill during the transition to first grade. In addition, many of the indirect paths from early language to first-grade reading (WJ-R LetterWord results) were statistically significant. Results shown in Table 4 indicated that indirect paths were significant from 36-month language: through 54-month broad language (PLS) to first-grade decoding (WJ-R Letter-Word) (unstandardized coefficient $B=$ $.07, p<.05$ ); through 54-month phonological knowledge (WJ-R Incomplete Words) to first-grade decoding $(B=.05, p<.01)$; and through 54-month decoding to first-grade scores on the same test
$(B=.20, p<.01)$. Note that in this model when both broad language measures and vocabulary measures are included, only the broad measures of early language predict first-grade reading outcomes. That is, 54-month vocabulary did not predict to first-grade word recognition $(B=-.02)$. Both vocabulary and more comprehensive language play unique roles in first-grade reading, but when both are considered in tandem, comprehensive language plays the more prominent role.

Summed together, the indirect paths from 36-month language through 54-month coding skills to first-grade reading (WJ-R Letter-Word; total indirect path: $B=.33$ ) were substantive as well as individually statistically significant.

\section{Was Early Language Related to Third-Grade Reading Comprehension?}

There was also considerable evidence linking prekindergarten language to the early development of reading comprehension skills both directly and indirectly. Comprehensive language at 54 months $(\beta=.10, p<.01), 54-m o n t h$ WJ-R Picture Vocabulary $(\beta=.20$, $p<.01)$, and first-grade WJ-R Picture Vocabulary $(\beta=.20, p<$ $.01)$ all provided independent direct paths to third-grade reading comprehension (see Table 3). In addition, many of the indirect paths from all early measures of language to third-grade reading comprehension were also significant (see Table 4).

The indirect path from 36-month language through the 54month and Grade 1 oral language and coding skill measures to Grade 3 reading was significantly different from zero. Indirect contributions to Grade 3 reading through 54-month PLS comprehensive language were found through first-grade WJ-R Letter-Word Identification $(B=.08, p<.05)$, first-grade WJ-R Incomplete Words $(B=.06, p<.05)$, and first-grade WJ-R Picture Vocabulary $(B=.01, p<.05)$. Significant indirect contributions to Grade 3 reading through 54-month WJ-R Picture Vocabulary were found through first-grade WJ-R Incomplete Words $(B=.04)$ and first-grade WJ-R Picture Vocabulary $(B=.20, p<.01)$. Finally, significant indirect contributions to Grade 3 reading were found through both 54-month WJ-R Letter-Word Identification and 54-month WJ-R Incomplete Words to first-grade WJ-R Letter-Word Identification (respectively, $B=.21, p<.01$, and $B=.05, p<$ .01 ) and to first-grade WJ-R Incomplete Words (respectively, $B=.03, p<.01$, and $B=.08, p<.01)$. There was also evidence of an indirect path to Grade 3 reading through 54month WJ-R Letter-Word Identification to Grade $1 \mathrm{WJ}-\mathrm{R}$ Picture Vocabulary $(B=.06, p<.01)$. Altogether, the indirect path from 36-month language through all combinations of 54month and first-grade measures to third-grade reading was substantial $(B=.36)$.

In addition, 54-month measures of language were related indirectly to third-grade reading. As shown in Table 4, comprehensive language skill at 54 months was indirectly related to third-grade reading through first-grade WJ-R Picture Vocabulary $(B=.01$, $p<.05)$ and WJ-R Letter-Word Identification $(B=.03, p<.05)$. WJ-R Picture Vocabulary at 54 months related to third-grade reading through first-grade WJ-R Picture Vocabulary $(B=.08$, $p<.01)$. WJ-R Incomplete Words at 54 months related to thirdgrade reading through first-grade WJ-R Picture Vocabulary $(B=$ 
Table 4

Unstandardized Indirect Path Coefficients for the Comprehensive Model

\begin{tabular}{|c|c|c|}
\hline Path & $B$ & $S E$ \\
\hline \multicolumn{3}{|l|}{ From 36-month to 54-month outcomes } \\
\hline \multicolumn{3}{|l|}{ Reynell total language 36 months $\rightarrow$} \\
\hline PLS 54 months $\rightarrow$ WJ-R Letter-Word Grade 1 & $.07 *$ & .03 \\
\hline WJ-R Vocabulary 54 months $\rightarrow$ WJ-R Letter-Word Grade 1 & .00 & .01 \\
\hline WJ-R Letter-Word 54 months $\rightarrow$ WJ-R Letter-Word Grade 1 & $.20 * *$ & .02 \\
\hline WJ-R Incomplete Words 54 months $\rightarrow$ WJ-R Letter-Word Grade 1 & $.05^{* *}$ & .02 \\
\hline \multicolumn{3}{|l|}{ From 54-month language and coding skills to Grade 3 reading } \\
\hline \multicolumn{3}{|l|}{ PLS 54 months $\rightarrow$} \\
\hline WJ-R Vocabulary Grade $1 \rightarrow$ WJ-R Passage Comprehension Grade 3 & $.01 *$ & .006 \\
\hline WJ-R Letter-Word Grade $1 \rightarrow$ WJ-R Passage Comprehension Grade 3 & $.03 *$ & .02 \\
\hline WJ-R Incomplete Words Grade $1 \rightarrow$ WJ-R Passage Comprehension Grade 3 & .004 & .003 \\
\hline \multicolumn{3}{|l|}{ Vocabulary 54 months $\rightarrow$} \\
\hline WJ-R Vocabulary Grade $1 \rightarrow$ WJ-R Passage Comprehension Grade 3 & $.08 * *$ & .01 \\
\hline WJ-R Letter-Word Grade $1 \rightarrow$ WJ-R Passage Comprehension Grade 3 & -.01 & .02 \\
\hline WJ-R Incomplete Words Grade $1 \rightarrow$ WJ-R Passage Comprehension Grade 3 & .007 & .003 \\
\hline \multicolumn{3}{|l|}{ WJ-R Incomplete Words 54 months $\rightarrow$} \\
\hline WJ-R Vocabulary Grade $1 \rightarrow$ WJ-R Passage Comprehension Grade 3 & $.02 * *$ & .006 \\
\hline WJ-R Letter-Word Grade $1 \rightarrow$ WJ-R Passage Comprehension Grade 3 & $.05 * *$ & .02 \\
\hline WJ-R Incomplete Words Grade $1 \rightarrow$ WJ-R Passage Comprehension Grade 3 & $.01 *$ & .006 \\
\hline \multicolumn{3}{|l|}{ WJ-R Letter-Word Identification 54 months $\rightarrow$} \\
\hline WJ-R Vocabulary Grade $1 \rightarrow$ WJ-R Passage Comprehension Grade 3 & $.03 * *$ & .007 \\
\hline WJ-R Letter-Word Grade $1 \rightarrow$ WJ-R Passage Comprehension Grade 3 & $.22 * *$ & .02 \\
\hline WJ-R Incomplete Words Grade $1 \rightarrow$ WJ-R Passage Comprehension Grade 3 & .008 & .004 \\
\hline
\end{tabular}

From 36-month Language to Grade 3 Reading

Reynell total language 36 months $\rightarrow$ PLS 54 months $\rightarrow$

WJ-R Vocabulary Grade $1 \rightarrow$ WJ-R Passage Comprehension Grade 3

WJ-R Letter-Word Grade $1 \rightarrow$ WJ-R Passage Comprehension Grade 3

WJ-R Incomplete Words Grade $1 \rightarrow$ WJ-R Passage Comprehension Grade

Reynell total language 36 months $\rightarrow$ Vocabulary 54 months $\rightarrow$

WJ-R Vocabulary Grade $1 \rightarrow$ WJ-R Passage Comprehension Grade 3

WJ-R Letter-Word Grade $1 \rightarrow$ WJ-R Passage Comprehension Grade 3

WJ-R Incomplete Words Grade $1 \rightarrow$ WJ-R Passage Comprehension Grade 3

Reynell total language 36 months $\rightarrow$ WJ-R Incomplete Words 54 months $\rightarrow$

WJ-R Vocabulary Grade $1 \rightarrow$ WJ-R Passage Comprehension Grade 3

WJ-R Letter-Word Grade $1 \rightarrow$ WJ-R Passage Comprehension Grade 3

WJ-R Incomplete Word Grade $1 \rightarrow$ WJ-R Passage Comprehension Grade 3

Reynell total language 36 months $\rightarrow$ WJ-R Letter-Word 54 months $\rightarrow$

WJ-R Vocabulary Grade $1 \rightarrow$ WJ-R Passage Comprehension Grade 3

WJ-R Letter-Word Grade $1 \rightarrow$ WJ-R Passage Comprehension Grade 3

WJ-R Incomplete Words Grade $1 \rightarrow$ WJ-R Passage Comprehension Grade 3

$\begin{array}{cc}.07 * & .03 \\ .08 * & .03 \\ .06 * & .03 \\ & \\ .20 * * & .02 \\ -.00 & .008 \\ .04 * & .01 \\ & \\ -.00 & .01 \\ .05 * * & .02 \\ .08 * * & .01 \\ & \\ .06 * * & .01 \\ .21 * * & .02 \\ .03 * * & .01\end{array}$

Note. $\quad$ Reynell $=$ Reynell Developmental Language Scales; WJ-R $=$ Woodcock-Johnson Psycho-Educational Battery-Revised; PLS = Preschool Language Scale.

$* p<.05 . * * p<.01$

$.02, p<.01)$, WJ-R Letter-Word Identification $(B=.05, p<$ $.01)$, and WJ-R Incomplete Words $(B=.01, p<.05)$. WJ-R Letter-Word Identification at 54 months was related through firstgrade WJ-R Picture Vocabulary $(B=.03, p<.01)$ and first-grade WJ-R Letter-Word Identification $(B=.22, p<.01)$. These analyses indicated that language at 54 months contributed to reading comprehension skills in third grade, both through the indirect paths from 54-month comprehensive language $(B=.05)$ and WJ-R Picture Vocabulary $(B=.08)$ and the direct paths from 54-month comprehensive language $(B=.07)$ and WJ-R Picture Vocabulary $(B=.08)$.

\section{Were Early Coding Skills Related to First-Grade Reading (Letter-Word Identification and Word Recognition)?}

The 54-month and first-grade measures of coding skills were also significantly associated with subsequent measures of language, coding skills, and reading. The 54-month measure of phonological skills (WJ-R Incomplete Words) was moderately associated with the first-grade score on the same test $(\beta=.22, p<.01)$ and with the first-grade WJ-R Letter-Word scores $(\beta=.10, p<$ $.01)$. The 54-month measure of WJ-R Letter-Word Identification was strongly associated with the first-grade score on the same test 


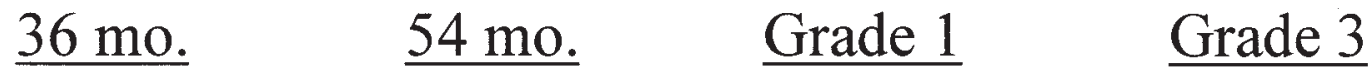

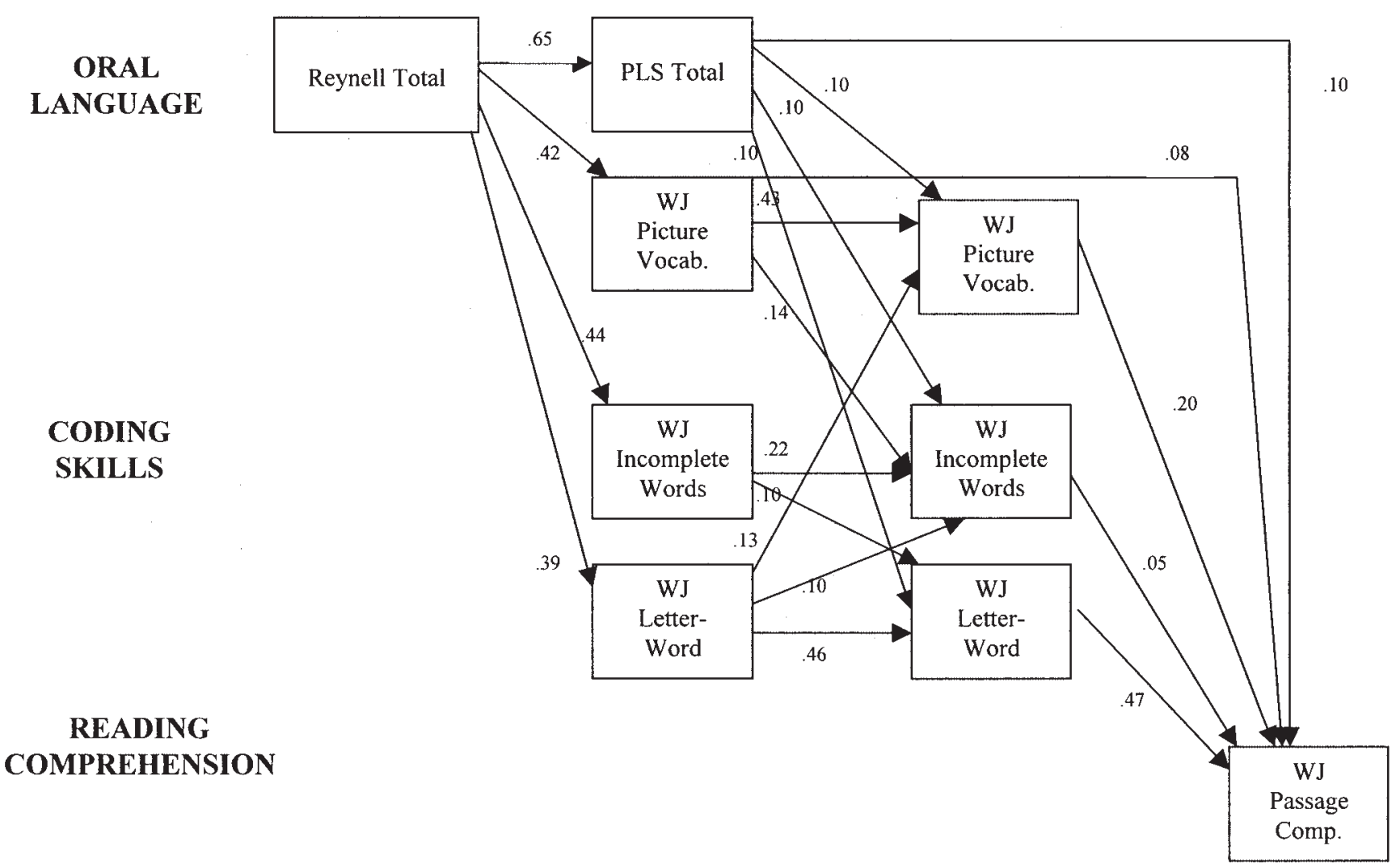

Figure 3. Path analyses for the comprehensive model. Nonsignificant paths and their correlations are not presented in the figure (see Tables 3 and 4). Reynell = Reynell Developmental Language Scales; PLS = Preschool Language Scale; WJ = Woodcock-Johnson Psycho-Educational Battery-Revised; Vocab. = Vocabulary; Comp. $=$ Comprehension.

$(\beta=.46, p<.01)$ and modestly related to first-grade WJ-R Picture Vocabulary $(\beta=.10, p<.01)$ and WJ-R Incomplete Words $(\beta=.13, p<.01)$.

\section{Were Early Coding Skills Related to Third-Grade Reading Comprehension?}

Early coding skills showed indirect associations with thirdgrade reading comprehension through first-grade coding skills. Neither of the 54-month measures of coding skills related directly to third-grade comprehension in preliminary analyses, although both 54-month WJ-R Incomplete Words and WJ-R Letter-Word Identification showed significant indirect paths. Significant indirect paths included 54-month WJ-R Incomplete Words through first-grade WJ-R Picture Vocabulary $(B=.02, p<.01)$, WJ-R Letter-Word Identification $(B=.05, p<.01)$, and WJ-R Incomplete Words $(B=.01, p<.05)$; while 54 -month WJ-R LetterWord Identification showed significant indirect paths through first-grade WJ-R Picture Vocabulary $(B=.03, p<.01)$ and WJ-R Letter-Word Identification $(B=.22, p<.01)$. The total indirect path to third-grade reading comprehension from 54-month WJ-R Incomplete Words $(B=.08)$ and 54-month WJ-R Letter-
Word Identification $(B=.25)$ indicated that prekindergarten coding skills provided independent prediction of first-grade reading skills and provided prediction of third-grade reading skills indirectly through first-grade vocabulary and decoding rather than directly.

\section{Socioeconomic Status (SES) Differences}

The results thus far were conducted for the entire sample. It was at least possible that differences in some of the findings between studies of early reading, however, were a product of the different populations used to test the models. That is, Storch and Whitehurst (2002), among many others, used exclusively low-income, highrisk children to evaluate the role of oral language in first-grade reading ability. To examine whether the findings reported above would be similar for both low- and high-risk children, we conducted one further analysis. We ran a series of comparisons for SES subgroups to examine whether the model was equally predictive for low-SES and high-SES children. On the basis of the income-to-needs ratio (mean from 6 months to third grade), we defined three SES subgroups: high, medium, and low. The lowincome group was defined as having an income-to-needs ratio of 
less than 2 and included 287 children (25.29\% of the sample). The medium-income group was defined as those with an income-toneeds ratio from 2 to 4 and included 450 children (39.65\% of the sample). Finally, 398 children ( $35.07 \%$ of the sample) were identified as in the high-income bracket, with income-to-needs ratios greater than 4. By constraining all the paths in the model, we first tested SES group differences for overall relations among the constructs in the model. The chi-square differences indicated that there was a group difference among the three SES groups. Pairwise comparisons followed, and the high-SES group emerged as significantly different from the other two groups.

To examine where the relations in the model produced differences, we then conducted SES group comparisons for each of the blocks of paths (e.g., the paths depicted in Figure 2). If there was a significant SES group difference in any block of paths, further comparisons for each path in the block and pairwise comparisons among the three SES groups followed. Importantly, there were no differences among groups in the paths from oral language at 54 months to reading skill in first grade, $\chi^{2}(4)=2.89, p=.58$. In fact, only two paths emerged as significant. First, the path from oral language development at 36 months to language at 54 months, $\chi^{2}(4)=12.53, p<.05$, revealed a smaller magnitude of prediction from the Reynell score to the PLS scores for those in the high-SES group $(B=.57, p<.01)$ than for those in the other two groups $(B=.64, p<.01$ for the medium-SES group, and $B=.66, p<$ .01 for the low-SES group). The SES groups did not differ in the path from Reynell scores to WJ-R Vocabulary. Second, there was a significant difference among groups in the path from coding skills in first grade to passage reading at third grade, $\chi^{2}(3)=$ $11.02, p<.05$. The WJ-R Letter-Word score significantly predicted the WJ-R Passage Comprehension score in all groups. In the low-SES group $(B=.57, p<.01)$, however, it did so to a greater extent than it did in either the high-SES group $(B=.51$, $p<.01)$ or the medium-SES group $(B=.42, p<.01)$. No group difference emerged between the SES groups in the path from WJ-R Incomplete Words to third-grade reading. These findings, including group comparison statistics for separate paths, are presented in Table 5.

\section{Discussion}

In this study, prospective longitudinal data from the NICHD Study of Early Child Care and Youth Development were used to investigate the role of early oral language skills and coding skills in reading outcomes in preschool and early elementary school. We predicted that oral language abilities would offer a foundation for both school readiness and later reading achievement. We predicted that along with coding skills, oral language would not only be important for building preliteracy skills such as phonological awareness and letter word skills but would also make a unique contribution to concurrent and later reading comprehension. Further, within oral language skills, we anticipated that broad language skills would be more predictive of concurrent preschool coding skills and reading achievement in first and third grade than would vocabulary skills alone.

These predictions were largely upheld. Early comprehensive oral language skills at age 3 were directly related to both comprehensive language and vocabulary at 54 months and to code-related skills in phonological knowledge. Thus, language at 3 years did relate directly to some, though not all, code-related skills at 54 months. The relation between language at 3 years and word recognition (WJ-R Letter-Word Identification) was mediated through 54-month oral language and phonemic knowledge. The fact that language at age 3 did not directly relate to 54-month WJ-R Letter-Word decoding might be accounted for by the strong and significant correlation between comprehensive language skill at 3 years and that at 54 months $(r=.73)$.

As expected from prior research, there was high concurrent intercorrelation between all of the 54-month oral and code-based skills. More impressively, and in contrast to prior research (Bryant et al., 1990; Storch \& Whitehurst, 2002; Whitehurst \& Lonigan, 2001), 54-month comprehensive oral language competence (though not vocabulary) related both indirectly and directly to first-grade word recognition and to third-grade reading comprehension. This was true for children from both the higher and lower SES groups. Even though comprehensive language ability was highly correlated with concurrent vocabulary $(r=.63)$, it is worth noting that broad language skills added unique variance to the

Table 5

Summary of Socioeconomic Status (SES) Group Differences

\begin{tabular}{|c|c|c|c|c|c|c|c|c|c|c|c|c|}
\hline \multirow[b]{3}{*}{ SES } & \multicolumn{6}{|c|}{$\begin{array}{c}\text { Oral } 36 \text { months } \rightarrow \text { Oral } 54 \text { months } \\
\chi^{2}(4)=12.531^{*} \\
(\text { high } \neq \text { low, medium })\end{array}$} & \multicolumn{6}{|c|}{$\begin{array}{c}\text { Code skills Grade } 1 \rightarrow \text { Reading Grade } 3 \\
\chi^{2}(3)=11.02^{*} \\
(\text { low } \neq \text { medium, high })\end{array}$} \\
\hline & \multicolumn{3}{|c|}{$\begin{array}{l}\text { Reynell } \rightarrow \text { PLS } \\
\chi^{2}(2)=9.91^{* *}\end{array}$} & \multicolumn{3}{|c|}{$\begin{array}{c}\text { Reynell } \rightarrow \text { WJPV } \\
\chi^{2}(2)=.58\end{array}$} & \multicolumn{3}{|c|}{$\begin{aligned} \text { WJIW } & \rightarrow \text { WJPC } \\
\chi^{2}(2) & =4.76\end{aligned}$} & \multicolumn{3}{|c|}{$\begin{array}{l}\text { WJLW } \rightarrow \text { WJPC } \\
\chi^{2}(2)=9.67 * *\end{array}$} \\
\hline & $B$ & $S E$ & $\beta$ & $B$ & $S E$ & $\beta$ & $B$ & $S E$ & $\beta$ & $B$ & $S E$ & $\beta$ \\
\hline High & $.77 * *$ & .06 & .57 & $.44^{* *}$ & .05 & .38 & .07 & .05 & .14 & $.39^{* *}$ & .03 & .51 \\
\hline Medium & $.97 * *$ & .06 & .64 & $.41^{* *}$ & .05 & .38 & .00 & .05 & .00 & $.38 * *$ & .04 & .42 \\
\hline Low & $1.10 * *$ & .07 & .66 & $.37 * *$ & .07 & .33 & $.17 * *$ & .06 & .14 & $.54 * *$ & .04 & .57 \\
\hline
\end{tabular}

Note. $\quad$ Reynell $=$ Reynell Developmental Language Scales; PLS $=$ Preschool Language Scale; WJPV $=$ WJ-R Picture Vocabulary; WJIW $=$ WJ-R Incomplete Words; WJPC = WJ-R Passage Comprehension; WJLW = WJ-R Letter-Word Identification; WJ-R = Woodcock-Johnson PsychoEducational Battery-Revised.

$* p<.05 . * * p<.01$. 
prediction of prereading scores and reading comprehension in our model.

The results of this study permit an expansion and a reassessment of the role of oral language in reading during the transition to school. These results, for example, build on current models that stress the important role of oral language skills in early reading. As Dickinson et al. (2003) explained, "Most studies of early literacy during the preschool years have failed to fully examine the interrelationships among abilities and thus have underestimated the contribution of oral language to early reading" (p. 473). They also force us to reassess our operational definition of oral language as consisting of either vocabulary alone or more comprehensive oral language skills that include vocabulary along with measures of semantics and grammar.

\section{Expanding Prior Research}

The predictive value of oral language skills in this model expands on prior research in at least four ways. First, the majority of studies in the literature extend only from kindergarten to second grade, with a minority beginning as early as 4 years of age (though see Chaney, 1992, 1998; Dickinson \& Tabors, 2001). This model offers a wide-angle lens on the changing interrelations between oral language skills and reading over time. By starting at 36 months of age, the model also disentangles some of the directionality problems faced in prior research. At 36 months of age, there is variability in general language acquisition and vocabulary but rather limited metalinguistic competence (Hirsh-Pasek, Gleitman, \& Gleitman, 1978). That is, although some children can find a rhyme for fish, they do not generally have phonological awareness at this age (Chaney, 1992; Smith \& Tager-Flusberg, 1982). Thus, in the current model one can assume that the comprehensive oral skills at 36 months drive the 54-month oral and code-based skills rather than the reverse.

Second, looking at a model from 36 months of age has the further advantage that it bridges research in language with research in preschool reading readiness and later reading comprehension. Research exists that links the quality of conversation at home and in child care to language ability at age 3 (see, e.g., Hart \& Risley, 1995, 1999; McCartney, 1984; NICHD Early Child Care Research Network, 2000). Few studies have projected relations between environment and language outcome at ages beyond 3 years (e.g., Hart \& Risley, 1999; Snow, 1983, 1991; Snow et al., 1998; Snow \& Dickinson, 1991; Snow, Tabors, \& Dickinson, 2001). This research allows one to add to the literature by showing how even earlier language environments might promote or hinder not only subsequent language ability but also reading competence.

The current results expand prior research in yet a third way by examining a diverse and more normative sample than has generally been included in longitudinal studies of early reading ability. Some studies used only middle-class children (e.g., Burgess \& Lonigan, 1998; Senechal \& LeFevre, 2002). Others, such as that of Storch and Whitehurst (2002), tested a comprehensive model of early reading development but used only Head Start children in their samples (see also Dickinson et al., 2003). Storch and Whitehurst (2002) cautioned researchers that their model might not generalize to middle- and upper-class children. The results from the current study do not suffer from the sample limitations of prior studies. Given current interest in promoting early reading, it is urgent that researchers use broad sampling techniques when studying reading readiness and the transition to school.

In fact, using a broader sample enabled us not only to look for general trends but also to investigate the ways in which more normative findings might vary across different socioeconomic or risk conditions. In this study, for example, only two findings or paths distinguished children from different socioeconomic levels. The first finding was that the relationship between oral language at age 3 and language skills at 54 months was even stronger for children in the low- and middle-income groups than it was for children in the high-SES group. The finding in the high-SES, low-risk children is a bit puzzling. On the one hand, we found that age 3 language was not as highly correlated with 54-month language when we looked at the broad language measure. When the vocabulary measure was used, the high-SES children's correlation was equivalent to those of the other groups.

Why then might this effect show up only for the broad language scores? Possibly, this finding arises because the higher SES children are already in a rich language environment. They have such high language scores and such a truncated range of scores at 36 months, and with two measures that tap essentially the same skills, it is more difficult to find correlations that are as strong for these children as it is for children with a more varied level of early language skill. Note that this does not mean that the higher SES children showed no correlation between 36-month language and later language, only that the relationship demonstrated for this particular test was smaller than that seen with lower SES children.

The second finding fits well within the current reading literature (Storch \& Whitehurst, 2002): Decoding skills in first grade were more closely related to third-grade reading ability for children from lower socioeconomic homes. Again, this finding does not mean that there was no correlation between first-grade decoding skills and reading for children from more privileged homes. Rather, it suggests that the relation is even more critical for children from lower income environments. These children are less likely to have the rich language environments that tend to foster early letter-to-sound learning (Senechal \& LeFevre, 2002).

The current results expand on prior research in yet a fourth way by controlling for maternal verbal intelligence. This control for verbal intelligence might reflect a number of different implicit impacts on children's early language and later reading. It might, for example, be an indirect control of children's intelligence. Maternal verbal intelligence is related to general intelligence, and given the genetic heritability of intelligence, it is possible that when we control for mother's verbal ability, we are also implicitly controlling for the child's intelligence.

Alternatively, maternal verbal intelligence might be a proxy for other factors such as the verbal stimulation that the child receives in the home. Parents with higher verbal intelligence are likely to talk more with their children and hence to provide a richer language environment for children. Richer language environments promote language skills in children and hence better reading skills (Hart \& Risley, 1995; Huttenlocher, Vasilyeva, Cymerman, \& Levine, 2002).

Given this control of maternal verbal intelligence, one might argue that the findings in this study more purely reflect the role of the child's oral language in later reading than they reflect the effects of child intelligence or even the child's particular language environment on developing code-related skills and reading com- 
prehension (Catts et al., 1999). This research offers some attempt to keep the child's inherited IQ constant while evaluating paths from oral language to reading.

\section{Reassessing Prior Research: The Role of Oral Language in Early and Later Reading}

The results from this research not only expand current findings but also force us to reassess the many strands that woven together build reading readiness (Scarborough, 2001). In broad strokes, our findings parallel those presented in the literature-albeit with a wider lens and a more diverse sample. Yet they also allow us to look at ways in which various aspects of oral language relate to code skills. In a number of studies, researchers have found that a complex array of oral language skills is critical for reading success, be it competence in syntax (Scarborough, 1990, 2001; Tunmer et al., 1988), discourse ability (Vernon-Feagans et al., 2001), or size of vocabulary (Goswami, 2001). Many, however, have focused on the role of vocabulary in early reading and on the role that this oral skill, in particular, plays in reading success (Chaney, 1998; Dickinson \& Snow, 1987; Dickinson et al., 2003; Share \& Leikin, 2004). In the current model with both broad-based oral language and vocabulary included, 54-month vocabulary did not independently relate to word decoding in first grade. Broad-based oral language skills at 54 months did, however, predict word decoding in first grade as well as reading comprehension in third grade. Notably, children's vocabulary in first grade also related positively and significantly to reading comprehension in third grade even with more comprehensive language included in the model. These results suggest, in contrast to the results of Storch and Whitehurst (2002) and consistent with claims by Dickinson et al. (2003), that preschool oral language skills feed directly into code-related skills during first grade rather than only affecting the phonological awareness skills that form a foundation for first-grade reading. These findings are also consistent with those from a recent investigation on the role that oral language skills among African American preschoolers play in their later reading skills (Craig, Connor, $\&$ Washington, 2003). Craig et al. found that syntactic complexity in preschoolers was more closely related to later reading skills in first and third grade than was vocabulary. Though it is still controversial whether oral language outweighs code skills in predicting later reading (Schatschneider et al., 2004), most recent investigations find that preschool oral language skills play an important role alongside code skills in predicting reading in the transition to school.

Why did this finding emerge in our model and not in the Storch and Whitehurst (2002) model? Several possibilities come to mind. First, it is possible that the difference in measures accounted for the divergent results in the two models. By way of example, one could argue that the incomplete words task from the WoodcockJohnson battery is as much a measure of vocabulary as it is a measure of phonological skills. To know that a spoken incomplete word like $b a$. . tub is representing bathtub, one needs to go beyond the sensitivity and manipulation of sounds to a word stored in the lexicon. Presumably, then, the more words one knows, the better one performs in this task. Looking at the incomplete words task as a phonological and a vocabulary measure, however, only strengthens the argument that reading is built jointly on sound manipulation and oral language. Further, the incomplete words task at 54 months was related to both 54-month and first-grade word recognition even when vocabulary was in the model. Thus, it is unlikely that differences in the two models emerged because the phonological segmentation task was really a test of vocabulary.

Similarly, the assessment of third-grade reading outcome may not be as extensive as those used in prior studies. Perhaps the cloze procedure task used to examine reading comprehension in the Woodcock-Johnson test is also a better measure of vocabulary than of reading per se. Again, if this reading task is only an alternative vocabulary test, one must ask why, with vocabulary in the model, 54-month language still exerted a small but significant effect on later reading ability above and beyond the effect of 54-month vocabulary? There is reason to believe, then, that the discrepancy in the findings between the Storch and Whitehurst (2002) model and our model is not simply driven by problems in the ways the constructs were assessed.

Second, our findings might have differed from those of Storch and Whitehurst (2002) because the current model included both broad-based oral language skills measured at two points in time and vocabulary assessed at two points in time. The oral language skill measure used by Storch and Whitehurst (2002) did go beyond vocabulary to include narrative skill and assessment of word structure, but these latter skills were only measured at one point in time. Hence the oral language latent variable in their structural equation model was heavily weighted toward vocabulary knowledge. Storch and Whitehurst (2002) wrote, "It is possible that the inclusion of other oral language measures, such as tests for auditory comprehension of language and grammatical sensitivity, may impact the strength of influence of the oral language domain on reading achievement" (p. 944). In some sense, then, even though they were careful to talk about a spectrum of oral abilities, these researchers joined others by operationally defining oral language in a narrow sense - as vocabulary development (Whitehurst \& Lonigan, 1998, 2001). This in turn could lead to the finding that oral skills are not as critical for early word decoding as are competencies in phonemic awareness. In contrast, the current study operationally defined language comprehensively as words, grammar, morphology, and discourse. Though vocabulary and phonemic knowledge are highly correlated with language development, these two skills alone do not account for all of the variability in language competence. By putting broad language, vocabulary, and phonemic knowledge in a joint model, we were able to differentially look at the way various components of oral language related to one another, to early reading readiness, and to later reading comprehension.

Finally, a third reason for the discrepancy between the two models could arise because, as noted above, the sample used for this research was more diverse than that generally used in longitudinal models of reading development. Perhaps the more normative sample has a richer language base to recruit in the service of learning generally and hence that language assists children in learning coding skills and word recognition as well as general reading comprehension. In this light, it is of particular interest that even when we examined the patterns of at-risk children, the results remained largely unchanged. Thus, any discrepancies between prior studies and ours cannot be solely attributable to changes in the sample populations.

Why would broader language skills be important for fostering both decoding skills during the transition to school and reading 
comprehension? There are two potential answers to this question. First, many have argued that in typically developing children, oral language abilities and reading mutually reinforce one another in the service of early reading competencies (Dickinson et al., 2003; Scarborough, 2001). This intertwining of multiple oral language skills and reading becomes even more evident when the system breaks down for children who have disabilities in particular areas of language development (Dickinson et al., 2003; Torgesen, Wagner, \& Rashotte, 1997). According to this argument, reading theorists who strive to look at various independent modules of language and their effect on mechanisms of reading create theoretical divisions in language development that are not real in the acquisition process. That is, recent evidence suggests that the size of a child's vocabulary is related to his or her phonological awareness (Goswami, 2001). Research also suggests that developments in vocabulary and grammar are intrinsically and perhaps even genetically related such that increases in vocabulary directly control growth in syntactic ability (Dionne, Dale, Boivin, \& Plomin, 2003). Dickinson et al. (2003) summed up this point by suggesting that oral language abilities might not be independent.

Second, and critically, researchers have looked for independent links between reading and language ability because reading is parasitic on language. In fact, one could argue that one of the most secure findings in the field of development concerns the relationship between phonological awareness and reading (Adams, 1990; Ehri et al., 2001; and see Dickinson et al., 2003, for a review). Yet language provides more than a foundation for reading per se. It offers a foundation for learning to learn. For example, even though there is no direct connection between mathematical concept learning and language, some posit that expressive language and metalinguistic competence might play a role in early mathematical thinking (Jordan, Huttenlocher, \& Levine, 1994; Pappas, Ginsburg, \& Jiang, 2003). Cocking and Mestre (1988) also reasoned that verbal abilities are the currency of education. Children need to understand instructions to learn mathematics and need to learn the "language of mathematics." Further, they need to communicate to teachers when they do not understand. One other potentially interesting argument for the general power of language in learning comes from a recent article on the evolution of language (Hauser, Chomsky, \& Fitch, 2002). Because language embeds categorization, recursion, and communication, it shares fundamental properties with many cognitive abilities. Perhaps this is why language skill is often used as a gauge of general intellect. As reading researchers posit interrelations between language and reading, it is important to note the role of early comprehensive language in learning as generally conceived.

\section{Implications of Using a More Broad-Based Definition of Language}

The ways in which we think of oral language and its relation to reading have consequences not only for our understanding of the mechanisms that lead to reading competence but also for our choices of interventions and assessment tools as we prepare children for the transition to school. If comprehensive language skills directly feed nascent reading, then interventions and assessments that focus only on phonemic awareness and vocabulary development will prove too narrow to support later academic achievement. This concern was raised by Storch and Whitehurst (2002): "Oral language skills should be an integral part of reading instruction beginning in preschool and throughout elementary school" (p. 944). Indeed, the finding that early comprehensive language is critical for success in later oral skills and code learning has consequences for when and how we begin to prepare children so that they are ready to learn. Environments rich in language stimulation and conversation will not only build general language skills but will also have the positive consequence of supplementing vocabulary and metalinguistic skills. The reverse is not necessarily true. That is, simply teaching vocabulary and phonemic awareness, although perhaps necessary, would not be sufficient to buttress general language skills.

These findings also have consequences for the assessments that U.S. legislators put into place to ensure that No Child [is] Left Behind. Current assessments for reading readiness with young children are built on models of reading that view oral skills narrowly. The National Reporting System being administered to half a million Head Start children in the United States, for example, contains two measures of English language competence, one that focuses on vocabulary and one that assesses letter names (see Meisels \& Atkins-Burnett, 2004, for a critique). Although these offer a first step in national assessment, the research reported in this article suggests that some measure of more comprehensive language would be more appropriate (see also Hirsh-Pasek, Kochanoff, Newcombe, \& de Villiers, 2005; Kochanoff, Hirsh-Pasek, Newcombe, \& Weinraub, 2003).

The findings reported in this article, then, are of both theoretical and practical consequence. These data provide an expansion of prior models investigating mechanisms of reading and offer a more comprehensive picture of the role that language plays in early reading readiness and during the transition to school. Data from the NICHD Study of Early Child Care and Youth Development compel us to reexamine the ways in which early language feeds into later oral language and code-based competencies and force us to reevaluate the ways in which we operationalize oral language in future models of reading development. Together these findings also suggest future directions for assessment and intervention.

\section{References}

Adams, M. (1990). Beginning to read: Thinking and learning about print. Cambridge, MA: MIT Press.

Arbuckle, J. L. (1997). Amos (Version 3.6) [Computer software]. Chicago: Small Waters.

Biemiller, A. (1999). Language and reading success. Cambridge, MA: Brookline Books.

Bishop, D. V. M. (1991). Developmental reading disabilities: The role of phonological processing has been overemphasized. Mind and Language, 6, 97-101.

Bishop, D. V. M., \& Adams, C. (1990). A prospective study of the relationship between specific language impairment, phonological disorders and reading retardation. Journal of Child Psychology and Psychiatry and Allied Disciplines, 31, 1027-1050.

Bollen, K. (1990). A comment on model evaluation and modification. Multivariate Behavioral Research, 25, 181-185.

Browne, M. W., \& Cudek, R. (1993). Alternative ways of assessing model fit. In K. A. Bollen (Ed.), Structural equations with latent variables. New York: Wiley.

Bryant, P., MacLean, M., \& Bradley, L. (1990). Rhymes, language and children's reading. Applied Psycholinguistics, 11, 237-252.

Burgess, S. R., \& Lonigan, C. J. (1998). Bidirectional relations of phono- 
logical sensitivity and prereading abilities: Evidence from a preschool sample. Journal of Experimental Child Psychology, 70, 117-141.

Catts, H. W., Fey, M. E., Zhang, X., \& Tomblin, J. R. (1999). Language basis of reading and reading disabilities: Evidence from a longitudinal investigation. Scientific Studies of Reading, 3, 331-361.

Chaney, C. (1992). Language development, metalinguistic skills, and print knowledge in 3-year-old children. Applied Psycholinguistics, 13, 485514

Chaney, C. (1998). Preschool language and metalinguistic skills are links to reading success. Applied Psycholinguistics, 15, 371-394.

Cocking, R., \& Mestre, J. (1988). Introduction: Considerations of language mediators of mathematics learning. In R. Cocking \& J. Mestre (Eds.), Linguistic and cultural influences on learning mathematics (pp. 3-16). Hillsdale, NJ: Erlbaum.

Craig, H. K., Connor, C. M., \& Washington, J. A. (2003). Early positive predictors of later reading comprehension for African American students: A preliminary investigation. Language, Speech \& Hearing Services in Schools, 14, 31-43.

Dickinson, D., McCabe, A., Anastasopoulos, L., Peisner-Feinberg, E., \& Poe, M. (2003). The comprehensive language approach to early literacy: The interrelationships among vocabulary, phonological sensitivity, and print knowledge among preschool-aged children. Journal of Educational Psychology, 95, 465-481.

Dickinson, D. K., \& Snow, C. E. (1987). Interrelations among pre-reading and oral language skills in kindergarteners from two social classes. Early Childhood Research Quarterly, 2, 1-25.

Dickinson, D. K., \& Tabors, P. O. (Eds.). (2001). Beginning literacy with language: Young children learning at home and school. Baltimore: Brookes.

Dionne, G., Dale, P., Boivin, M., \& Plomin, R. (2003). Genetic evidence for bidirectional effects of early lexical and grammatical development. Child Development, 74, 394-412.

Dunn, L. M., \& Dunn, L. M. (1981). Peabody Picture Test-Revised manual for Forms $L$ and $M$. Circle Pines, MN: American Guidance Service.

Ehri, L. C., Nunes, S. R., Willows, D. M., Schuster, B. V., Yaghoub-Zadeh, Z., \& Shanahan, T. (2001). Phonemic awareness instruction helps children learn to read: Evidence from the National Reading Panel's metaanalysis. Reading Research Quarterly, 36, 250-287.

Goswami, U. (2001). Early phonological development and the acquisition of literacy. In S. B. Newman \& D. K. Dickinson (Eds.), Handbook of early literacy research (pp. 111-125). New York: Guilford Press.

Hart, B., \& Risley, T. R. (1995). Meaningful differences in the everyday experience of young American children. Baltimore: Brookes.

Hart, B., \& Risley, T. R. (1999). The social world of children learning to talk. Baltimore: Brookes

Hauser, M. D., Chomsky, N., \& Fitch, T. (2002). The faculty of language: What is it, who has it, and how did it evolve? Science, 298, 1569-1579.

Hirsh-Pasek, K., Gleitman, L., \& Gleitman, H. (1978). What did the brain say to the mind? A study of the detection and report of ambiguity by young children. In A. Sinclair, R. J. Jarvella, \& W. J. M. Levelt (Eds.), The child's conception of language (pp. 97-132) New York: SpringerVerlag.

Hirsh-Pasek, K., Kochanoff, A., Newcombe, N., \& de Villiers, J. (2005). Using scientific knowledge to inform preschool assessment: Making the case for "Empirical validity." Social Policy Report, 19, 3-19.

Hu, L. T., \& Bentler, P. (1999). Cutoff criteria for fit indexes in covariance structure analysis: Conventional criteria versus new alternatives. Structural Equation Modeling, 6, 1-55.

Huttenlocher, J., Vasilyeva, M., Cymerman, E., \& Levine, S. (2002). Language input and child syntax. Cognitive Psychology, 45, 337-374.

Jordan, N. C., Huttenlocher, L., \& Levine, S. C. (1994). Assessing early arithmetic abilities: Effects of verbal and nonverbal response types on the calculation performance of middle- and low-income children. Learning and Individual Differences, 6, 413-432.

Kochanoff, A., Hirsh-Pasek, K., Newcombe, N., \& Weinraub, M. (2003). Using science to inform preschool assessment (Summary Report of the Temple University Forum on Preschool Assessment). Phildadelphia, PA: Temple University.

MacKinnon, D. P., Lockwood, C. M., Hoffman, J. M., West, S. G., \& Sheets, V. (2002). A comparison of methods to test mediation and other intervening variable effects. Psychological Methods, 7, 83-104.

McCartney, K. (1984). Effects of quality of day-care environment on children's language development. Developmental Psychology, 20, 244 260 .

Meisels, S., \& Atkins-Burnett, A. (2004). Public policy viewpoint. The Head Start National Reporting System: A critique. Young Children, 59, $64-66$.

Menyuk, P., Chesnick, J., Liebergott, J. W., Korngold, B., D’Agostino, R., \& Belanger, A. (1991). Predicting reading problems in at-risk children. Journal of Speech and Hearing Research, 34, 893-903.

NICHD Early Child Care Research Network. (2000). The relation of child care to cognitive and language development. Child Development, 71, 960-980.

NICHD Early Child Care Research Network. (2001). Nonmaternal care and family factors in early development: An overview of the NICHD Study of Early Child Care. Applied Developmental Psychology, 22, 457-492.

Pappas, S., Ginsburg, H., \& Jiang, M. (2003). SES differences in young children's metacognition in the context of mathematical problem solving. Cognitive Development, 18, 431-450.

Reynell, J. K., \& Gruber, C. P. (1977). Reynell Developmental Language Scales. Los Angeles: Western Psychological Services.

Roth, F. B., Speece, D. L., Cooper, D. H., \& de la Paz, S. (1996) Unresolved mysteries: How do metalinguistic and narrative skills connect with early reading? Journal of Special Education, 30, 257-277.

Scarborough, H. S. (1990). Very early language deficits in dyslexic children. Child Development, 61, 1728-1743.

Scarborough, H. S. (2001). Connecting early language and literacy to later reading (dis)abilities: Evidence, theory, and practice. In S. B. Neuman \& D. K. Dickinson (Eds.), Handbook of early literacy research (pp. 97110). New York: Guilford Press.

Schatschneider, C., Fletcher, J., Francis, D., Carlson, C., \& Foorman, B. (2004). Kindergarten prediction of reading skills: A longitudinal comparative analysis. Journal of Educational Psychology, 96, 265-282.

Senechal, M., \& LeFevre, J. (2002). Parental involvement in the development of children's reading skill: A five-year longitudinal study. Child Development, 73, 445-460

Share, D. L., \& Leikin, M. (2004). Language impairment at school entry and later reading disability: Connections at lexical versus supralexical levels of reading. Scientific Studies of Reading, 8, 87-110.

Shonkoff, J., \& Phillips, D. (Eds.). (2000). From neurons to neighborhoods. Washington, DC: National Academy Press.

Smith, C., \& Tager-Flusberg, H. (1982). Metalinguistic awareness and language development. Journal of Experimental Psychology, 34, 449468.

Snow, C. E. (1983). Literacy and language: Relationships during the preschool years. Harvard Educational Review, 53, 165-189.

Snow, C. E. (1991). The theoretical basis for relationships between language and literacy in development. Journal of Research in Childhood Education, 6, 5-10.

Snow, C. E., Burns, M. S., \& Griffin, P. (Eds.) (1998). Preventing reading difficulties in young children. Washington, DC: National Academy Press.

Snow, C. E., \& Dickinson, D. K. (1991). Skills that aren't basic in a new conception of literacy. In E. M. Jennings \& A. C. Purves (Eds.), Literate 
systems and individual lives: Perspectives on literacy and schooling (pp. 179-191). Albany, NY: SUNY Press.

Snow, C. E., Tabors, P. O., \& Dickinson, D. K. (2001). In D. K. Dickinson \& P. O. Tabors (Eds.), Beginning literacy with language: Young children learning at home and school (pp. 1-30). Baltimore: Brookes.

Sobel, M. E. (1982). Asymptotic confidence intervals for indirect effects in structural equation models. In S. Leinhart (Ed.), Sociological methodology (pp. 290-312). San Francisco: Jossey-Bass.

Steiger, J. H., \& Lind, J. C. (1980, June). Statistically based tests for the number of common factors. Paper presented at the annual meeting of the Psychometric Society, Iowa City, IA.

Storch, S., \& Whitehurst, G. (2001). The role of family and home in the literacy development of children from low-income backgrounds. New Directions for Child and Adolescent Development, 92, 53-68.

Storch, S. A., \& Whitehurst, G. J. (2002). Oral language and code-related precursors to reading: Evidence from a longitudinal model. Developmental Psychology, 38, 934-947.

Torgesen, J. K., Wagner, R. K., \& Rashotte, C. A. (1997). Prevention and remediation of severe reading disabilities: Keeping the end in mind. Scientific Studies of Reading, 1, 217-234.

Tunmer, W. E., Herriman, M., \& Nesdale, A. R. (1988). Metalinguistic abilities and beginning reading. Reading Research Quarterly, 23, 134158.

Tunmer, W. E., \& Nesdale, A. R. (1985). Phonemic segmentation and beginning reading. Journal of Educational Psychology, 77, 418-427.

Vellutino, F. R., Scanlon, D. M., Sipay, E. R., Small, S. G., Pratt, A., Chen, R., \& Denckla, M. B. (1996). Cognitive profiles of difficult-to-mediate and readily remediated poor readers: Early intervention as a vehicle for distinguishing between cognitive and experiential deficits as basic causes of specific reading disability. Journal of Educational Psychology, $88,601-638$.

Vernon-Feagans, L., Hammer, C., Miccio, A., \& Manlove, E. (2001). Early language and literacy skills in low-income African American and Hispanic children. In S. B. Newman \& D. K. Dickinson (Eds.), Handbook of early literacy research (pp. 192-210). New York: Guilford Press.

Whitehurst, G. J., \& Lonigan, C. J. (1998). Child development and emergent literacy. Child Development, 69, 848-872.

Whitehurst, G. J., \& Lonigan, C. J. (2001). Emergent literacy: Development from prereaders to readers. In S. B. Neuman \& D. K. Dickinson (Eds.), Handbook of early literacy research (pp. 11-29). New York: Guilford Press.

Woodcock, R. W., \& Mather, N. (1989). WJ-R-R Tests of Cognitive Ability Standard Battery: Examiner's manual. In R. W. Woodcock \& M. B. Johnson, Woodcock-Johnson Psycho-Educational Battery-Revised. Allen, TX: DLM Teaching Resources.

Woodcock, R. W., \& Mather, N. (1989-1990). WJ-R-R Tests of Achievement: Examiner's manual. In R. W. Woodcock \& M. B. Johnson, Woodcock-Johnson Psycho-Educational Battery—Revised. Allen, TX: DLM Teaching Resources.

Zimmerman, I. L., Steiner, V. G., \& Pond, R. E. (1979). Preschool Language Scale-Revised edition. San Antonio, TX: The Psychological Corporation.

Received April 12, 2004

Revision received September 4, 2004

Accepted September 9, 2004 